\title{
Clinical identification and severity in patients with COVID-19
}

\author{
María L. Hernández ${ }^{1,2,4}$, Raúl Romero-Cabello ${ }^{1,2 *}$, Ulises Hernández-Dávalos ${ }^{3}$, Samuel Sevilla-Fuentes ${ }^{1}$, \\ Manuelita Zavala-Pineda ${ }^{1,4}$, Silvia N. Martínez-Jiménez ${ }^{1,4}$, Margarito T. Santos-González ${ }^{1,2}$, \\ Miguel Á. Solís-Bravo ${ }^{1}$, Mario Sierra-Garduñoㅇ, Joaquín Moreno-Moreno ${ }^{1}$, and Juan J. Fonseca Mata ${ }^{1}$ \\ ${ }^{1}$ Department of Infectious Diseases, Hospital General de México; ${ }^{2}$ Faculty of Medicine, National Autonomous University of Mexico; ${ }^{3}$ Department of \\ Internal Medicine, Hospital General de México; ${ }^{4}$ School of Medicine, National Polytechnic Institute. Mexico City, Mexico
}

\begin{abstract}
The clinical evaluation of the patient with COVID-19 allows better care, application of safety criteria and preventive measures. The disease progresses from mild to severe and critical. In this work, is evaluated in patients with COVID-19 clinical format to identify moderate to severe stages of the disease. Following a cohort of male and female patients over 18 years of age admitted to the Infectology Service of the General Hospital of Mexico. Each patient is studied using the "COVID-19 Infectology" clinical format and in the first 24 hours of admission, a real-time RT-PCR molecular test is performed for SARS-CoV-2 infection. 65 patients classified as severe COVID-19 were studied, the RT-PCR was positive in 60 patients and negative in 5, clinical data did not differ from the positive ones and the 5 negative were considered false negative cases of the molecular test. There were no differences between positives and negatives with Fisher's test, and no difference in age, comorbidities, or prognostic evaluation with Student's $t$ test. The conclusion is that the clinical format "COVID-19 Infectology" allows to recognize the cases and identify those that are in a severe evolution.
\end{abstract}

Keywords: Clinical identification Covid-19. Identification severe Covid-19. Clinical evaluation Covid-19.

\section{Introduction}

When dealing with patients with COVID-19, diagnosing the disease in time and providing early management, even if it isn't etiological due to the fact we don't have it, enables us to improve patient care and, to the extent possible, prevent progression to severe disease. As such, doctors in clinical practice faced with this disease need to refine their evaluation, as clinical evolution is extremely variable.

The incubation period for SARS-CoV-2 ranges from 2 to 14 days from contact with the infecting person. The signs appear as an acute disease that evolves from mild to severe or critical as follows: $80 \%$ of patients have mild to moderate disease, $14 \%$ severe, and $5 \%$ critical. Many patients develop a mild, uncomplicated, flu-like upper respiratory infection with non-specific symptoms such as moderate fever, dry cough, nasal congestion, fatigue, anorexia, general malaise, myalgia, dysphagia, and headaches; $90 \%$ of patients have more than one of these symptoms. Some patients also have gastrointestinal symptoms such as diarrhea, nausea, vomiting and abdominal pain ${ }^{1,2}$.

The evolution of COVID-19 may also give rise to arthralgia, dyspnea, anosmia or dysosmia, dysgeusia or ageusia, hyporexia, sputum production, conjunctivitis, sore throat, mental confusion, dizziness, rhinorrhea, chest pain, hemoptysis, and skin disorders. There is so much clinical data available that we have grouped it into General, Algological (Table 1), Respiratory, Neurological

\section{Correspondence:}

*Raúl Romero-Cabello

E-mail: romerocabello@ idisalud.com
Available online: 07-03-2022

Date of reception: 22-06-2021

Date of acceptance: 18-11-2021

DOI: 10.24875/HGMX.21000048
Rev Med Hosp Gen Mex. 2022;85(1):7-16 www.hospitalgeneral.mx

0185-1063/@ 2021 Sociedad Médica del Hospital General de Mexico. Published by Permanyer. This is an open access article under the CC BYNC-ND license (http://creativecommons.org/licenses/by-nc-nd/4.0/). 
Table 1. General clinical manifestations in different series of patients

\begin{tabular}{|c|c|}
\hline $\begin{array}{l}\text { General clinical } \\
\text { manifestations }\end{array}$ & Algological manifestations \\
\hline Fever & Myalgia \\
\hline Shivering & Arthralgia \\
\hline General malaise & Arthralgia in the fingers \\
\hline Body pain & Lack of strength in the hands \\
\hline Dizziness & Pain in: \\
\hline Headache & Face \\
\hline Drowsiness & Oral mucosa \\
\hline Hemoptysis & Molars \\
\hline Fatigue - Weariness & Neck \\
\hline Lack of energy & Shoulders \\
\hline Weakness & Arms \\
\hline Hyporexia & Wrists \\
\hline Facial edema & Hands \\
\hline Tachycardia & Hips \\
\hline Sweating & Knees \\
\hline Head & Legs \\
\hline Neck & Thighs \\
\hline Forehead & Ankles \\
\hline Head and neck & Feet \\
\hline Feet & Heels \\
\hline Middle body & Soles of the feet \\
\hline Cold sweating & Testicular pain \\
\hline \multirow[t]{2}{*}{ Edema in the fingers } & Renal fossa pain \\
\hline & Intense pain throughout the body \\
\hline
\end{tabular}

(Table 2), Gastrointestinal, Ocular and Cutaneous (Table 3) clinical manifestations. In general, patients that develop moderate disease have respiratory symptoms such as a cough, dyspnea and tachypnea; unlike the more severe disease, with mild pneumonia with no signs of severity, but with oxygen saturation in ambient air of less than $90 \%$ and/or a respiratory rate greater than 30 breaths a minute, or severe pneumonia with acute respiratory distress syndrome. $5 \%$ of the latter patients may develop critical illness with cardiac injury, septic shock, or multi-organ dysfunction ${ }^{3}$.
Table 2. Clinical respiratory and neurological manifestations

\begin{tabular}{|c|c|}
\hline Respiratory & Neurological \\
\hline Pharyngeal pain & $\begin{array}{l}\text { Anosmia - Hyposmia - } \\
\text { Hyperosmia }\end{array}$ \\
\hline Pharyngeal burning & Ageusia - Dysgeusia \\
\hline Dry throat & Facial itching \\
\hline $\begin{array}{l}\text { Sore throat, sensation of } \\
\text { something stuck (obstruction) }\end{array}$ & Tinnitus \\
\hline Pharynx sores & Numbness \\
\hline Tickly throat & Hands \\
\hline Mouth sores & Legs \\
\hline Pimply tongue & Arms \\
\hline Dysphonia & $\begin{array}{l}\text { Sensation of edema in the } \\
\text { feet }\end{array}$ \\
\hline Coughing & Sometimes burning heat \\
\hline Nasal congestion & Face \\
\hline Sputum & Eyes \\
\hline Dry nose & Ears \\
\hline Rhinorrhea & Hands \\
\hline Mucus with blood from the nose & Feet \\
\hline Epistaxis & Knees \\
\hline $\begin{array}{l}\text { Sensation of fullness in the } \\
\text { middle of the face }\end{array}$ & Calves \\
\hline Otic fullness & Thighs \\
\hline Ear pain & Legs \\
\hline Tinnititus & $\begin{array}{l}\text { Considerable heat with no } \\
\text { fever }\end{array}$ \\
\hline Sneezing & $\begin{array}{l}\text { Sensation of inner heat in } \\
\text { the torso, throat and feet }\end{array}$ \\
\hline Dyspnea & $\begin{array}{l}\text { Burning sensation in the } \\
\text { back }\end{array}$ \\
\hline Chest pain & Cold \\
\hline Retrosternal pain & Chest \\
\hline Burning sensation in the chest & Feet \\
\hline $\begin{array}{l}\text { Burning sensation in the chest } \\
\text { when breathing in air }\end{array}$ & Soles of the feet \\
\hline Chest congestion & General \\
\hline $\begin{array}{l}\text { A sensation of obstruction in the } \\
\text { chest }\end{array}$ & Feeling cold when inhaling \\
\hline Sensation of blocked phlegm & Burning \\
\hline Back pain & Feet \\
\hline Burning sensation in the back & Toes \\
\hline
\end{tabular}


Table 2. Clinical respiratory and neurological manifestations (Continued)

\begin{tabular}{|l|l|}
\hline Respiratory & Neurological \\
\hline Rales & Soles of the feet \\
\hline Fine trembling of the \\
\hline hands \\
\hline Sweaty hands \\
\hline Insomnia \\
\hline Anguish \\
\hline Tingling \\
\hline Face \\
\hline Nose \\
\hline Hands \\
\hline Chest \\
\hline Abdomen \\
\hline Legs \\
\hline Pruritus \\
\hline Face \\
\hline Ears \\
\hline Body \\
\hline Feet \\
\hline Heaviness \\
\hline Head \\
\hline Feet \\
\hline Lack of strength \\
\hline
\end{tabular}

(Continues)

The evolution of patients is variable, and in some cases deterioration can occur in as little as 2 to 3 days, characterised by the presence of signs of pneumonia and ventilatory insufficiency, the patient has a grim appearance, worsens quickly and suffers from tachypnea. Signs of inspiratory crackles, rales, bronchial respiration, tachycardia, tachypnea and cyanosis should be looked out for and oxygen saturation is reduced. It should be pointed out that patients with COVID-19 can develop what has been called "silent hypoxia"; in these cases oxygen saturation drops to low levels and precipitates acute respiratory failure without
Table 2. Clinical respiratory and neurological manifestations (Continued)

\begin{tabular}{|l|l|}
\hline Respiratory & Neurological \\
\hline Hands \\
\hline Clumsy hands \\
\hline Bewilderment \\
\hline Confusion \\
\hline Disorientation \\
\hline $\begin{array}{l}\text { Non-specific discomfort } \\
\text { from the knees down }\end{array}$ \\
\hline Mouth sensation of rough \\
\hline lips and cheeks \\
\hline Cramp \\
\hline Feet \\
\hline Arms \\
\hline Tired feet \\
\hline Mild shaking \\
\hline Limbs \\
\hline Trembling voice, I feel \\
\hline shaky inside \\
\hline Stabbing pain in the chest \\
\hline and left armpit \\
\hline Numb fingers \\
\hline Numb hands \\
\hline Facial pain \\
\hline Scalp pain \\
\hline Numb tongue \\
\hline Numb legs \\
\hline
\end{tabular}

the previous presence of data on ventilatory difficulties ${ }^{3,4}$.

The measurement of oxygen saturation is essential and is interpreted as follows: between $95 \%$ and $99 \%$ normal; $91 \%$ to $94 \%$ mild hypoxia; $86 \%$ to $90 \%$ moderate hypoxia; and less than $86 \%$ severe hypoxia. This may vary slightly due to differences in the altitude above sea level where the person is.

The purpose of this work is to evaluate and identify patients with probable COVID-19 in need of in-hospital management using a clinical format. 


\section{Material and Method}

The study is conducted on a cohort of patients of 18 years of age or older diagnosed with COVID-19, admitted to the Infectious Diseases Department of the "Eduardo Liceaga" General Hospital of Mexico. Each patient was evaluated as follows:

Anyone with suspected COVID-19 requesting an appointment was granted one in the external appointments area of the Infectious Diseases department. A detailed clinical evaluation was carried out using the Clinical Format known as "COVID-19 Infectology" for the evaluation of suspected cases of COVID-19 classified as moderate and severe. This format is based on the assessment of the following clinical data grouped into three sections: A.- Fever, cough, and headache. B.- Arthralgia, myalgia, odynophagia, rhinorrhea, conjunctivitis and chest pain. C.- Dyspnea and oxygen saturation less than $90 \%$. The following severity criterion was then applied to identify the patients in need of hospitalization: at least two positive items from section $A$, at least one positive item from section $B$, and all positive items from section $\mathrm{C}$.

Once the evaluation had been carried out and the clinical diagnosis and scores had been established, the patients identified with a moderate to severe probability of COVID-19 were offered a hospital bed in the Department; those who accepted were then required to complete the acceptance and informed consent forms. A sample of nasopharyngeal and oropharyngeal exudate was taken within the first 24 hours of the patient being admitted to perform a real-time RT-PCR molecular test for SARS-CoV-2 infection; the sample was submitted to the Molecular Biology laboratory for the respective tests.

The descriptive statistical analysis consisted of determining the measures of central tendency and dispersion for the quantitative variables and percentages for the qualitative variables. For the inferential statistical analysis, a Fisher exact test was conducted for qualitative variables and a Student $t$ test for quantitative variables.

\section{Results}

65 patients were analysed, $39(60.0 \%)$ of were male and $26(40.0 \%)$ female. Table 4 illustrates the age breakdown of the 65 patients: less than 30 years of age: $3(4.6 \%) ; 31$ to 40 years of age: $7(10.8 \%) ; 41$ to 50 years of age: $16(24.6 \%) ; 51$ to 60 years of age: 20 (30.8\%); 61 to 70 years of age: $16(24.6 \%)$; and more than 70 years of age: $3(4.6 \%)$. The highest number of cases $(52(80 \%)$ occurred in people in the fourth, fifth and sixth decades of life, with an average age of $52.6 \pm 12.5$ years and a range of 24 to 83 years of age (Table 4).

The clinical manifestations observed in patients upon admission were classified in 4 groups: systemic, respiratory system, digestive system and others (Table 5). With regard to general symptoms, fever was registered in $87.7 \%$ (57); headache in $66.2 \%(43)$; general deterioration $55.4 \%$ (36); shivering in $41.5 \%$ (27); and irritability in $30.8 \%$ (twenty). As can be seen, the three symptoms with a percentage of over $50 \%$ were: fever, headache and general deterioration. The respiratory system registered cough in $92.3 \%$ (60); dyspnea in $86.2 \%$ (56); rhinorrhea and odynophagia in $30.8 \%(20)$; chest pain in $27.7 \%$ (18); polypnea in $15.4 \%$ (10); and cyanosis in $6.2 \%$ (4). The main manifestations in relation to the respiratory system were undoubtedly coughing and dyspnea. The digestive system featured diarrhea in $16.9 \%$ (11); abdominal pain in $15.4 \%$ (10); and vomiting in $9.2 \%$ (6). Other symptoms were: arthralgia in $56.9 \%$ (37); myalgia in $55.4 \%$ (36); and conjunctivitis in $4.6 \%$ (3); (Table 5).

All the patients were evaluated using the Call Scale to predict risk progression, and it was found that 13 were low risk, 24 medium risk and 28 high risk (Table 6).

The results of the real-time polymerase chain molecular test for SARS-CoV-2 were positive in 60 patients $(92.3 \%)$ and negative in 5 patients $(7.7 \%) ; 4$ of the latter being female and and 1 male.

$43(66.2 \%)$ of the 65 patients registered an improvement while they were in hospital and $22(33.8 \%)$ died.

\section{Discussion}

Despite the fact that COVID-19 is a new disease, it is clear that clinical studies are essential to identifying it in the patient. The "COVID-19 Infectology" clinical format was used in this study to identify severe cases in the 65 patients admitted to the Department of Infectious Diseases, who were already hospitalised, and a detailed clinical study confirmed the presence of fever, coughing and headache, arthralgia, myalgia, odynophagia, rhinorrhea, conjunctivitis and chest pain, along with dyspnea and hypoxemia. Oxygen saturation of less than $90 \%$, fever, headache, general deterioration, coughing, dyspnea, arthralgia and myalgia stood out as the most frequent data; Other authors have already 
Table 3. Clinical gastrointestinal, ocular and cutaneous manifestations

\begin{tabular}{|c|c|c|}
\hline Gastrointestinal & Ocular & Cutaneous \\
\hline Dry mouth & Photophobia & Erythematous lesions on the fingers and soles of the feet \\
\hline \multirow[t]{2}{*}{ Scalded tongue } & Ocular erythema & Intense peeling of the soles of the feet \\
\hline & Eye pain & Ecchymosis \\
\hline Abundant night sialorrhea & Itchy eyes & Legs \\
\hline Discomfort when swallowing & Burning eyes & Buttocks \\
\hline Belching & Periorbital edema & Hyperpigmentation of the genitals \\
\hline Nausea & Tearing & Urticaria \\
\hline Vomiting & Eye secretion & Gallbladder \\
\hline Hiccups & Eyelid edema & Petechiae \\
\hline Abdominal pain & & Acroischemia \\
\hline Epigastralgia & & Rash \\
\hline Transprandial fullness & & Erythematous \\
\hline Abdominal distension & & Macular \\
\hline Rumbling & & Maculopapular \\
\hline Flatulence & & Perifollicular \\
\hline Diarrhea & & Purpuric \\
\hline Constipation & & Morbilliform \\
\hline Rectal tenesmus & & Erythema \\
\hline \multirow[t]{14}{*}{ Fetid stool } & & Multi-form \\
\hline & & Palmar \\
\hline & & Facial \\
\hline & & Enanthem \\
\hline & & Pityriasis rosea \\
\hline & & Necrotic lesions \\
\hline & & Rash on the face, back and chest \\
\hline & & Red spots in the mouth \\
\hline & & Pale skin \\
\hline & & Red and sweaty hands and feet \\
\hline & & Itchy penis with burning sensation, appearance of ulcers and significant dryness \\
\hline & & Dry calves \\
\hline & & Hand edema \\
\hline & & Dry lips \\
\hline
\end{tabular}

used evaluation models, also known as triage systems ${ }^{5}$.

All the patients were evaluated using the Call Scale to predict risk progression, and it was found that
24 (36.9\%) were medium risk and 28 (43.1\%) high risk (Table 6). It should be pointed out that the patients' outcomes were as follows: Discharge due to improvement 43 (66.2\%) and death 22 (33.8\%). When 
Table 4. Breakdown of age of patients with COVID-19

\begin{tabular}{|l|c|c|c|c|c|c|}
\hline Age & \multicolumn{2}{|c|}{ PCR+ } & \multicolumn{2}{c|}{ PCR- } & \multicolumn{2}{c|}{ Total } \\
\hline (years) & No. & $\%$ & No. & $\%$ & No. & $\%$ \\
\hline$<30$ & 3 & 5.0 & & & 3 & 4.6 \\
\hline $31-40$ & 6 & 10.0 & 1 & 20.0 & 7 & 10.8 \\
\hline $41-50$ & 13 & 21.7 & 3 & 60.0 & 16 & 24.6 \\
\hline $51-60$ & 20 & 33.3 & & & 20 & 30.8 \\
\hline $61-70$ & 15 & 25.0 & 1 & 20.0 & 16 & 24.6 \\
\hline$>70$ & 3 & 5.0 & & & 3 & 4.6 \\
\hline Total & 60 & 100.0 & 5 & 100.0 & 65 & 100.0 \\
\hline
\end{tabular}

correlating the CALL scale results with evolution to death, it was found that most of the deaths involved patients from the high-risk group, illustrating that the CALL scale did predict the risk of progression in our patients and, as such, that this scale is quite useful, as other researchers have published ${ }^{6}$ (Fig. 1).

As we have pointed out, the clinical manifestations of this disease are very varied and when reviewing the literature on the subject we found that other authors have published series of cases with reports on different clinical characteristics. We have compiled comparison tables to illustrate the consistency with the findings registered in our patients, whereby we suggest that special attention needs to be paid to researching and acknowledging all this clinical data when caring for patients with COVID-192,4,7-11 (Tables 7 and 8).

The real-time polymerase chain reaction test registered SARCoV2 infection in 60 of the 65 patients. It should be pointed out that the 5 negative cases involved four females and one male, and the main clinical manifestations were fever, headache, coughing and dyspnea; these being no different to the symptoms registered in the 60 positive cases to RT-PCR, which were fever and headache in systemic data and coughing and dyspnea in respiratory data (Table 5).

The definitive test for SARS-CoV-2 is the real-time reverse transcriptase-polymerase chain reaction (RT$\mathrm{PCR}$ ) test. It is regarded as highly specific, however the sensitivity of the test ranges from $60 \%$ to $97 \%$, compared to specificity of $89 \%$. The sensitivity varies in relation to the time elapsed since exposure to SARS-CoV-2, in such a way that there are $100 \%$ false negatives on the first day after exposure and $67 \%$ on the fourth day. The false negative rate remains at $38 \%$ and reaches its lowest point of $20 \%$ three days after the onset of symptoms. The false negative rate begins to rise again from this time on, reaching $66 \%$ on the $21^{\text {st }}$ day after exposure. Hence, false negatives are a real clinical problem, and multiple negative tests may be required in a single case to be sure disease can be ruled out. We need to bear in mind that negative results in the SARS-CoV-2 RT-PCR test do not rule out the possibility of infection, particularly if the patient has highly suspicious clinical manifestations of COVID-19.

This test involves the use of biological products from the nasopharynx, oropharynx or saliva, and targets the following RNA genes: envelope (ENV), nucleocapsid $(\mathrm{N})$, spike (S), RNA polymerase, RNA-dependent (RdRp) and ORF1. The identification of viral RNA is achieved at the threshold of the cycle ( $\mathrm{Ct}$ is the number of replication cycles required to produce a fluorescent signal), which varies in the days of evolution and reaches its maximum point in the first week of the onset of symptoms; positivity decreases at week 3 and then becomes undetectable. It also varies in accordance with differences in $\mathrm{Ct}$ for the different genes in question. The biological product to be studied causes variations in the results of the test; positivity in bronchoalveolar lavage (93\%), followed by sputum (72\%), nasal swab (63\%) and pharyngeal swab $(32 \%)^{5}$. Moreover, false negative results occur due to unreliable sampling techniques, in particular nasopharyngeal swabs, and due to technical errors and the contamination of reagents ${ }^{6,12-15}$. Despite the fact that this technique features high sensitivity and specificity, its effectiveness depends on proper processing, as there are many factors that can affect the results of the test, including the effective collection of samples using a swab in the nasopharyngeal area, as this region in which the virus undergoes a higher rate of replication, in addition to transporting samples to the laboratory in the appropriate manner with no contamination ${ }^{16}$. Another factor we need to bear in mind is the RT-PCR technique, which needs to be carried out in the proper manner in order to guarantee the maximum performance of the test, which involves obtaining a good quality RNA, as this material is susceptible to degradation due to the action of ribonucleases (RNAs). To this end, this material needs to be kept in cold conditions during handling. Another relevant factor is the concentration of the PCR components, as the improper amount of reagents used to amplify samples inhibits the amplification of genes ${ }^{17}$.

The main clinical symptoms included in the evaluation carried out in our study with the use of the 
Table 5. Clinical data on patients with COVID-19

\begin{tabular}{|c|c|c|c|c|c|c|c|}
\hline \multirow{2}{*}{$\begin{array}{l}\text { Patients with } \\
\text { General symptoms }\end{array}$} & \multicolumn{2}{|c|}{ PCR + } & \multicolumn{2}{|c|}{ PCR - } & \multicolumn{2}{|c|}{ Total } & \multirow[t]{2}{*}{$\mathbf{P}$} \\
\hline & No. & $\%$ & No. & $\%$ & No. & $\%$ & \\
\hline Fever & 53 & 88.3 & 4 & 80.0 & 57 & 87.7 & 0.493 \\
\hline Headache & 40 & 66.7 & 3 & 60 & 43 & 66.2 & 0.555 \\
\hline General deterioration & 34 & 56.7 & 2 & 40.0 & 36 & 55.4 & 0.397 \\
\hline Shivering & 26 & 43.3 & 1 & 20.0 & 27 & 41.5 & 0.302 \\
\hline Irritability & 19 & 31.7 & 1 & 20.0 & 20 & 30.8 & 0.509 \\
\hline Gastrointestinal symptoms & No. & $\%$ & No. & $\%$ & No. & $\%$ & \\
\hline Diarrhea & 10 & 16.7 & 1 & 20.0 & 11 & 16.9 & 0.617 \\
\hline Abdominal pain & 10 & 16.7 & 0 & 0 & 10 & 15.4 & 0.421 \\
\hline Vomiting & 6 & 10.0 & 0 & 0 & 6 & 9.2 & 0.606 \\
\hline Other symptoms & No. & $\%$ & No. & $\%$ & No. & $\%$ & \\
\hline Arthralgia & 36 & 60 & 1 & 20 & 37 & 56.9 & 0.104 \\
\hline Myalgia & 34 & 56.7 & 2 & 40 & 36 & 55.4 & 0.397 \\
\hline Conjunctivitis & 3 & 5 & 0 & 0 & 3 & 4.6 & 0.783 \\
\hline Respiratory symptoms & No. & $\%$ & No. & $\%$ & No. & $\%$ & \\
\hline Coughing & 56 & 93.3 & 4 & 80.0 & 60 & 92.3 & 0.339 \\
\hline Dyspnea & 52 & 86.7 & 4 & 80.0 & 56 & 86.2 & 0.538 \\
\hline Odynophagia & 20 & 33.3 & 0 & 0 & 20 & 30.8 & 0.148 \\
\hline Rhinorrhea & 18 & 30 & 2 & 40 & 20 & 30.8 & 0.491 \\
\hline Chest pain & 16 & 26.7 & 2 & 40.0 & 18 & 27.7 & 0.426 \\
\hline Polypnea & 10 & 16.7 & 0 & 0 & 10 & 15.4 & 0.421 \\
\hline Cyanosis & 4 & 6.7 & 0 & 0 & 4 & 6.2 & 0.72 \\
\hline
\end{tabular}

Table 6. CALL Score for patients with COVID-19

\begin{tabular}{|l|c|c|c|c|c|c|}
\hline \multirow{2}{*}{ Call Total } & \multicolumn{2}{|c|}{ PCR+ } & \multicolumn{2}{c|}{ PCR- } & \multicolumn{2}{c|}{ Total } \\
\cline { 2 - 7 } & No. & $\%$ & No. & $\%$ & No. & $\%$ \\
\hline 4 & 2 & 3.3 & & & 2 & 3.1 \\
\hline 5 & 4 & 6.7 & & & 4 & 6.2 \\
\hline 6 & 7 & 11.7 & & & 7 & 10.8 \\
\hline 7 & 8 & 13.3 & 2 & 40.0 & 10 & 15.4 \\
\hline 8 & 8 & 13.3 & & & 8 & 12.3 \\
\hline 9 & 5 & 8.3 & 1 & 20.0 & 6 & 9.2 \\
\hline 10 & 10 & 16.7 & 1 & 20.0 & 11 & 16.9 \\
\hline 11 & 10 & 16.7 & & & 10 & 15.4 \\
\hline 12 & 4 & 6.7 & 1 & 20.0 & 5 & 7.7 \\
\hline 13 & 2 & 3.3 & & & 2 & 3.1 \\
\hline Total & 60 & 100 & 5 & 100 & 65 & 100 \\
\hline
\end{tabular}

"COVID-19 Infectology" Clinical Format are fever, coughing and dyspnea, in addition to the other symptoms of headache, arthralgia, myalgia, chest pain, odynophagia, rhinorrhea and conjunctivitis, in addition to oxygen saturation of less than $90 \%$. When analysing the negative PCR cases, we see that the 5 negative patients registered the same clinical data as the 60 positive cases, reason for which they were regarded as being in the false negative range for the molecular test. A statistical analysis was conducted of the two groups using the Fisher test and the results show that the negative cases are no different clinically to the positive cases. Moreover, the student $t$ test shows that there is no difference in age, comorbidities or the Call scores ${ }^{6,18}$.

In relation to the development of variants of the virus, the United States government's Inter-Agency Group on SARS-CoV-2 has classified the genetic variants of the virus in 3 groups: Variants of interest, Variants of concern and Variants of high consequence. The first group includes the ETA variant, identified in the United Kingdom, the IOTA variant, identified in New York and the KAPPA variant, identified in India. The characteristics of these three variants are a possible reduction in 
Revista Médica del Hospital General de México. 2022;85(1)

Table 7. Clinical respiratory manifestations in different series of patients

\begin{tabular}{|l|c|c|c|c|c|c|c|c|}
\hline Symptoms & Lei P & Wang D & Guan W & Chen N & Huang Ch & Lechein JR & Chiesa-Estomba CM & Romero-Cabello R \\
\hline No. of patients & 204 & 138 & 1099 & 99 & 41 & 2579 & 542 & 65 \\
\hline Fever & 92.23 & 98.6 & 43.8 & 83 & 98 & 42.1 & 35.4 & 87.7 \\
\hline Myalgia & 14.56 & 34.8 & 14.9 & 11 & & 53.5 & 62.7 & 55.4 \\
\hline Dyspnea & & 31.2 & 18.7 & 31 & 55 & 45.2 & 5.8 & 86.2 \\
\hline Expectoration & & 26.8 & 33.7 & & 28 & 13 & 18.6 & \\
\hline Coughing & & & 67.8 & 82 & 76 & 55.2 & 43.6 & 92.3 \\
\hline Headache & & 6.5 & 13.6 & 8 & 8 & 59.8 & 72.5 & 66.2 \\
\hline Rhinorrhea & & & 4.8 & 4 & & & 7.4 & 30.8 \\
\hline Arthralgia & & & & & & 39.5 & & 56.9 \\
\hline Chest pain & & & & 2 & & 17.9 & & 27.7 \\
\hline
\end{tabular}

Table 8. Clinical gastrointestinal manifestations in different series of patients

\begin{tabular}{|l|c|c|c|c|c|}
\hline Symptoms & Lei P & Wang D & Lechein JR & Chiesa Estomba CM & Romero-Cabello R \\
\hline No of patients & 204 & 138 & 2579 & 542 & 65 \\
\hline Loss of appetite & 78.64 & 39.9 & 40.6 & 46.7 & \\
\hline Diarrhea & 33.98 & 10.1 & 31 & & 16.9 \\
\hline Vomiting & 3.88 & 3.6 & 17.5 & 19.9 & 15.4 \\
\hline Abdominal pain & 1.94 & 2.2 & & & 9.2 \\
\hline Nausea & & 10.1 & & & \\
\hline
\end{tabular}

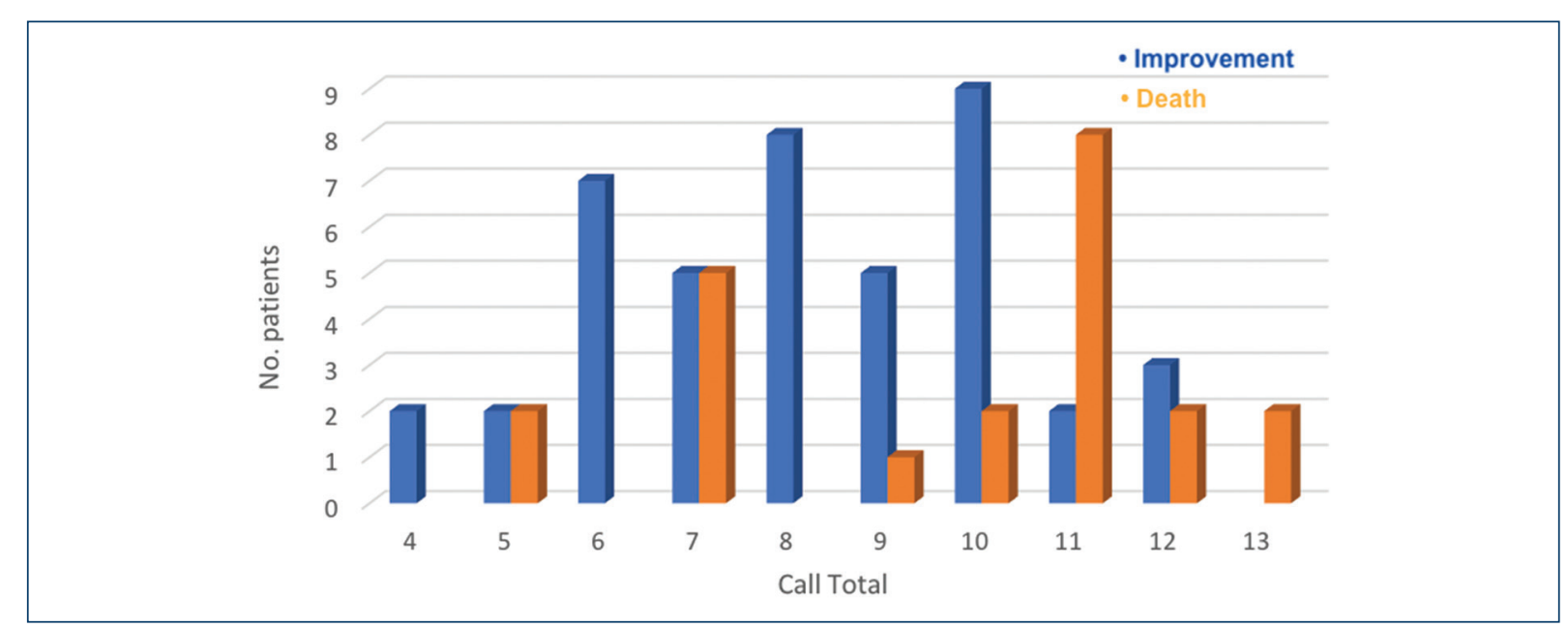

Figure 1. Call score and evolution of patients. Number of patients, improvement and death.

neutralisation with monoclonal antibodies and in neutralisation with convalescent sera and post-vaccination sera. This group also includes the LAMDA variant, identified in Peru, the EPSILON variant, identified in the United States, the THETA variant, identified in the Philippines and the ZETA variant, identified in Brazil. The 
characteristics of the latter variants have still not been clarified, and the MU variant, identified in Colombia, could pose the risk of immune evasion or resistance to vaccines.

The Variants of Concern group includes the ALPHA Variant, identified in the United Kingdom, with increased levels of transmission and potential greater severity in hospitalisations and deaths. The BETA Variant, identified in South Africa, with increased levels of transmission, less susceptibility to monoclonal antibody treatment and less neutralisation with convalescent and post-vaccination sera, and the DELTA Variant, identified in India, with increased levels of transmission, potential reduction in neutralisation in some monoclonal antibody treatments and a reduction in neutralisation using post-vaccination sera, can cause symptoms two to three days faster, in addition to more severe disease and a reduction in the efficacy of vaccines and treatment. Finally, the GAMMA variant, identified in Japan and Brazil, with a considerable reduction in susceptibility to monoclonal antibody treatment and less neutralisation of convalescent and post-vaccination sera.

The variants of high consequence that have not yet been identified would cause problems in diagnostic tests, less efficacy with regard to vaccines, less response to treatment and generate more serious cases $^{19-21}$.

\section{Conclusion}

The clinical evaluation of patients with COVID-19 and the use of evaluation models such as the "COVID-19 Infectology" Clinical Format enable us to recognise cases and to identify those that are progressing to severity. Given that this pathology features a large number of manifestations, the clinical physician requires a comprehensive evaluation in professional practice. The pulse oximeter is now an instrument that every clinical physician should use in the evaluation of patients on a daily basis.

\section{Funding}

We do not receive any type of financing.

\section{Conflict of interests}

The authors declare that they have no conflict of interest.

\section{Ethical disclosures}

Protection of human and animal subjects. The authors declare that no experiments were performed on humans or animals for this study.

Confidentiality of data. The authors declare that they have followed the protocols of their work center on the publication of patient data.

Right to privacy and informed consent. The authors have obtained the written informed consent of the patients or subjects mentioned in the article. The corresponding author is in possession of this document.

\section{References}

1. Li Q, Guan X, Wu P, Wang X, Zhou L, Tong Y, et al. Early Transmission dynamics in Wuhan, China, of novel coronavirus-infected pneumonia. N Engl J Med 2020;382:1199-207.

2. Huang C, Wang Y, Li X, Ren L, Zhao J, Hu Y, et al. Clinical features of patients infected with 2019 novel coronavirus in Wuhan, China. Lancet 2020;395:497-506.

3. Zhou F, Yu T, Du R, Fan G, Liu Y, Liu Z, et al. Clinical course and risk factors for mortality of adult inpatients with COVID-19 in Wuhan, China: a retrospective cohort study. Lancet 2020;395:1054-62.

4. Chen N, Zhou M, Dong X et al. Epidemiological and clinical characteristics of 99 cases of 2019 novel coronavirus pneumonia in Wuhan, China: a descriptive study. Lancet 2020; 395:507-13.

5. Kuriyama A, Urushidani $S$, Nakayama T. Five-level emergency triage systems: variation in assessment of validity. Emergency Medicine Journal 2017;34(11):703-710.

6. Dong Ji, Dawei Zhang, Jing $\mathrm{Xu}$, Zhu Chen, Tieniu Yang, Peng Zhao, Guofeng Chen, Gregory Cheng, Yudong Wang, Jingfeng B, et al. Prediction for Progression Risk in Patients With COVID-19 Pneumonia: The CALL Score. Clinical Infectious Diseases 2020;71(6):1393-1399.

7. Lei Pan, Mi Mu, Pengcheng Yang, Yu Sun, Runsheng Wang, Junhong Yan, Pibao Li, Baoguang Hu, Jing Wang, Chao Hu, Yuan Jin, Xun Niu, Rongyu Ping, Yingzhen Du, Tianzhi Li, Guogang Xu, Qinyong Hu, Lei Tu. Clinical Characteristics of COVID-19 Patients With Digestive Symptoms in Hubei, China: A Descriptive, Cross-Sectional, Multicenter Study. Am J Gastroenterol 2020;115:766-773.

8. Dawei Wang, Bo Hu, Chang Hu, Fangfang Zhu, Xing Liu, Jing Zhang, Binbin Wang, Hui Xiang, Zhenshun Cheng, Yong Xiong, Yan Zhao, Yirong Li, Xinghuan Wang, Zhiyong Peng. Clinical Characteristics of 138 Hospitalized Patients with 2019 Novel Coronavirus-Infected Pneumonia in Wuhan, China. JAMA 2020;7:E1-E9.

9. W. Guan, Z. Ni, Yu Hu, W. Liang, C. Ou, J. He, L. Liu, H. Shan, C. Lei, D.S.C. Hui, B. Du, L. Li, G. Zeng, K.-Y. Yuen, R. Chen, C. Tang, T. Wang, P. Chen, J. Xiang, S. Li, Jin-lin Wang, Z. Liang, Y. Peng, L. Wei, Y. Liu, Ya-hua Hu, P. Peng, Jian-ming Wang, J. Liu, Z. Chen, G. Li, Z. Zheng, S. Qiu, J. Luo, C. Ye, S. Zhu, N. Zhong. Clinical Characteristics of Coronavirus Disease 2019 in China. N Engl J Med 2020;382:1708-20.

10. Jerome R. Lechien, Carlos M. ChiesaEstomba, Liugi A. Varia, Giacomo De Riu, Giovanni Cammaroto, Younes Chekkouryldrissi, Marta Circiu, Lea Distinguin, Fabrice Journe, Christophe de Terwangn, Shahram Machayekh, Maria R. Barillari, Christian CalvoHenriquez, Stéphane Hans, Sven Saussez. Epidemiological, otolaryngological, olfactory and gustatory outcomes according to the severity of COVID19: a study of 2579 patients. Eur Arch Otorhinolaryngology 2021; doi.org/10.1007/s00405-02006548-w.

11. Carlos M. Chiesa-Estomba, Jerome R. Lechien, Patricia Portillo-Mazal, Federico Martínez, Jesús Cuauro-Sanchez, Christian Calvo-Henriquez, Sven Saussez. Olfactory and gustatory dysfunctions in COVID-19. First reports of Latin American ethnic patients. Am J Otolaryngol 2020;41: 102605

12. Wang W?, Xu Y?, Gao R?, et al. Detection of SARS-CoV-2 in different types of clinical specimens? JAMA. 2020;doi:10.1001/ jama.2020.3786.

13. World Health Organization. Laboratory testing for 2019 novel coronavirus (2019-nCoV) in suspected human cases. Interim guidance. 17 January 2020. WHO/2019-nCoV/laboratory/2020.3.

14. Nalla AK, Casto AM, Huang ML, Perchetti GA, Sampoleo R, Shrestha $L$ et al. Compararive performance of SARS-CoV-2 detection assays using seven different primer/probe sets and one assay kit. J Clin Microbiol 2020. doi:10.1128/JCM.557-20. 
15. Chan JF, Yip C, To K, Tang T, Wong S, Leung K, Fung A et al. Improved molecular diagnosis of COVID-19 by the novel, highly sensitive and specific COVID-19-RdRp/Hel real-time reverse transcriptasa-polymerasa chain reaction assay validated in vitro and with clinical specimen. J Clin Microbiol 2020. doi:10.1128/JCM.310-20.

16. Wyllie AL, Fournier J, Casanovas-Massana A, Campbell M, Tokuyama M, Vijayakumar P. Saliva or Nasopharyngeal Swab Specimens for Detection of SARS-CoV-2. N Engl J Med 2020; DOI: 10.1056/NEJMc2016359.

17. Dierdre B, Axell-House, Richa Lavingia, Megan Rafferty, Eva Clark, E. Susan Amirian, Elizabeth Y. Chiao. The estimation of diagnostic accuracy of tests for COVID-19: A scoping review. J Infect 2020;81(5): $681-97$
18. McNally M, et al. Validity of British Thoracic Society guidance (the CRB-65 rule) for predicting the severity of pneumonia in general practice: systematic review and meta-analysis. Br J Gen Pract 2010;60(579):e423-33.

19. Red Regional de Vigilancia Genómica de COVID-19 (COVIGEN), OPS Siguiendo de cerca las variantes del SARS-CoV-2 en las Américas. Disponible en: https://www.paho.org/es/historias/siguiendo-cerca-variantes-sars-cov-2-americas Consultado: 10/09/21.

20. Seguimiento de las variantes del SARS-CoV-2. OMS. Disponible en: https://www.who.int/es/activities/tracking-SARS-CoV-2-variants. Consultado: 10/09/21.

21. European Centre for Disease Prevention and Control. SARS-CoV-2 variants of concern as of 9 September 2021. Disponible en: https://www. ecdc.europa.eu/en/covid-19/variants-concern Consultado: 10/09/21. 